\title{
Ion-exchange Separators Suppressing Self-Discharge in Polymeric Supercapacitors
}

Kaiping Wang ${ }^{1+}$, Lulu Yao ${ }^{1+}$, Mehran Jahon ${ }^{2}$, Jiaxi Liu ${ }^{2}$, Matthew Gonzalez ${ }^{1}$, Ping Liu ${ }^{1}$, Vincent Leung ${ }^{2}$, Xinyu Zhang ${ }^{2}$, Tse Nga Ng1,2 *

${ }^{1}$ Materials Science Engineering Program, University of California San Diego, La Jolla, CA 92093, United States.

2 Department of Electrical and Computer Engineering, University of California San Diego, La Jolla, CA 92093, United States.

${ }^{+}$These authors contributed equally to this work

*Corresponding email: tnn046@ucsd.edu 

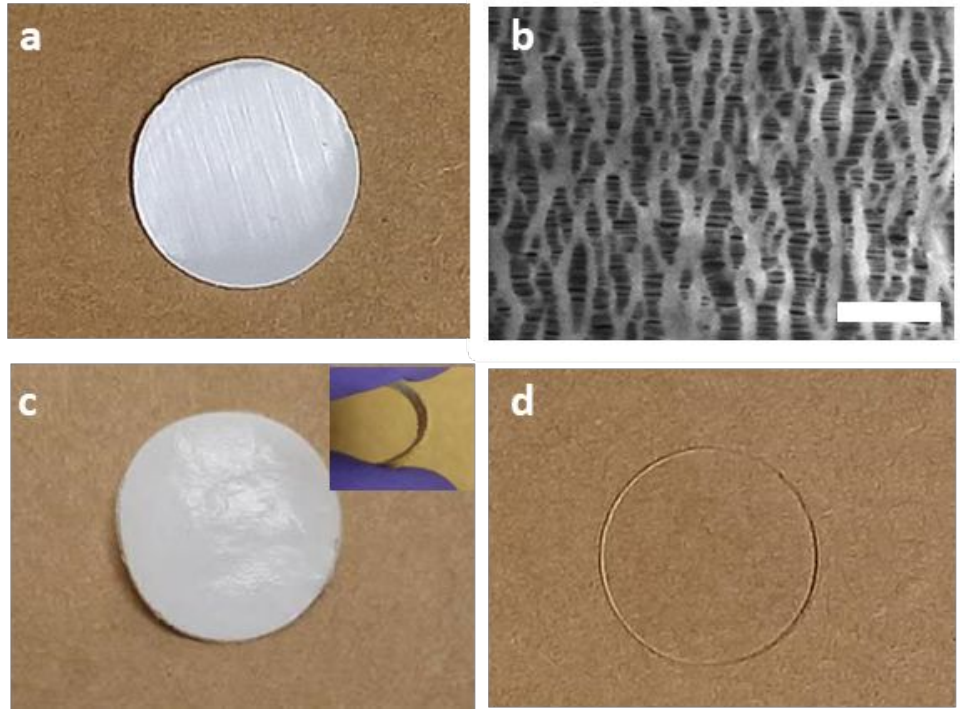

Figure S1. (a) Optical photograph of the commercial polypropylene (PP) separator (Celgard ${ }^{\mathrm{TM}}$ 3501). (b) SEM image of the PP film surface. Scale bar: 2 um. (c) Optical photograph of the sPS+PP separator. The inset shows the separator being bent. (d) Optical photograph of the Nafion ${ }^{\mathrm{TM}} 117$ separator. The diameter of each sample is $1.3 \mathrm{~cm}$. 

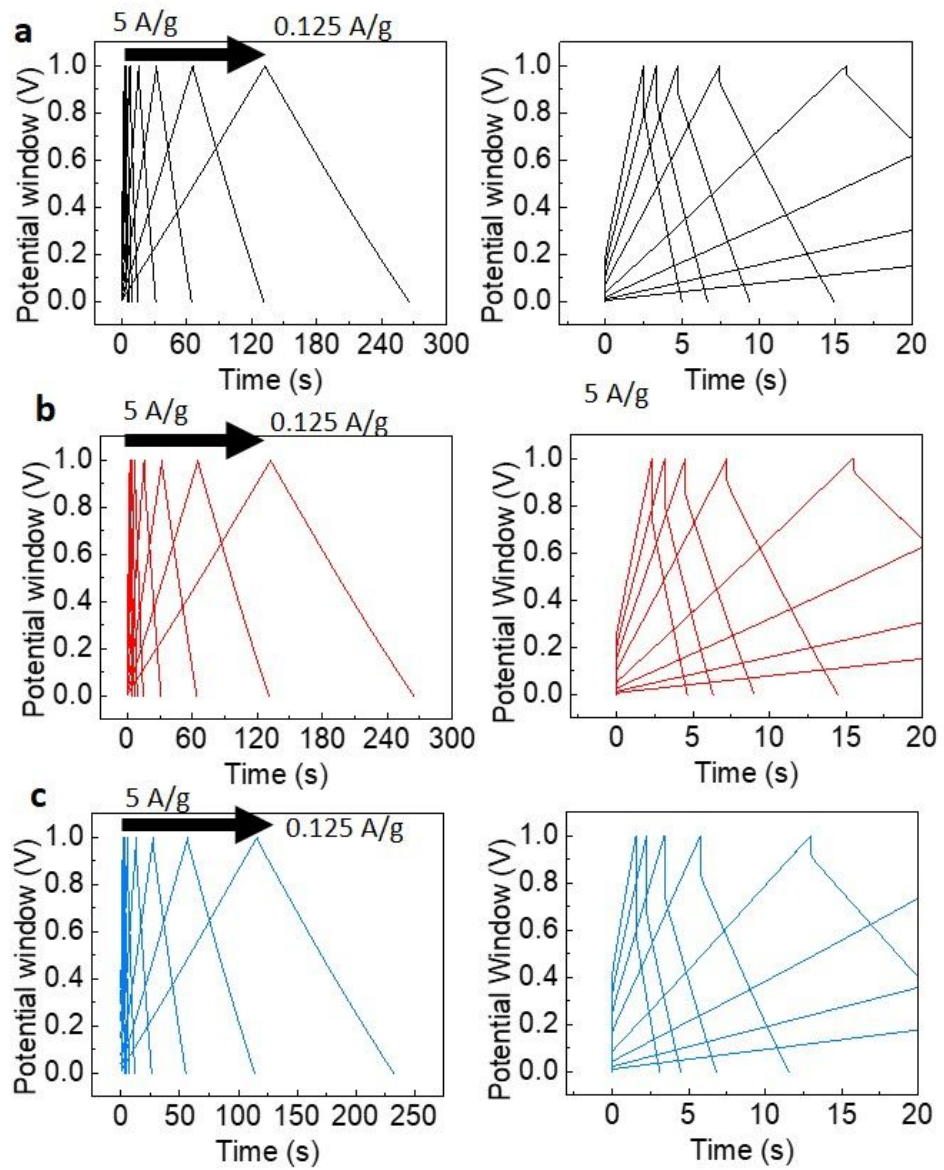

Figure S2. Galvanostatic charge-discharge curves of devices with the separator of (a) PP, (b) sPS+PP, and (c) sPTFE. The current inputs are $0.125,0.25,0.5,1,2,3,4$, and $5 \mathrm{~A} / \mathrm{g}$. The right column is zoomed in view of the curves at high current density (from $5 \mathrm{~A} / \mathrm{g}$ to $1 \mathrm{~A} / \mathrm{g}$ ). 
a

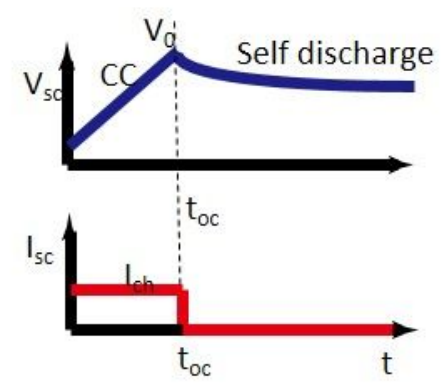

C

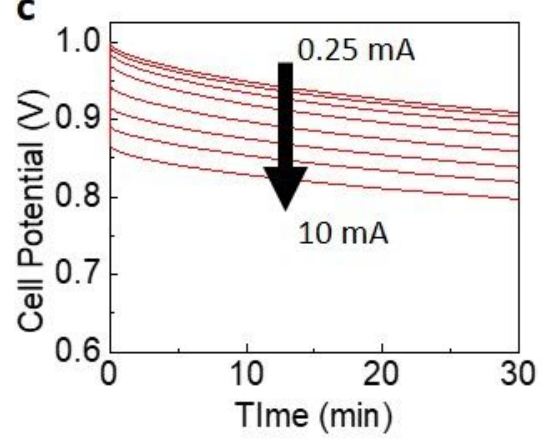

b
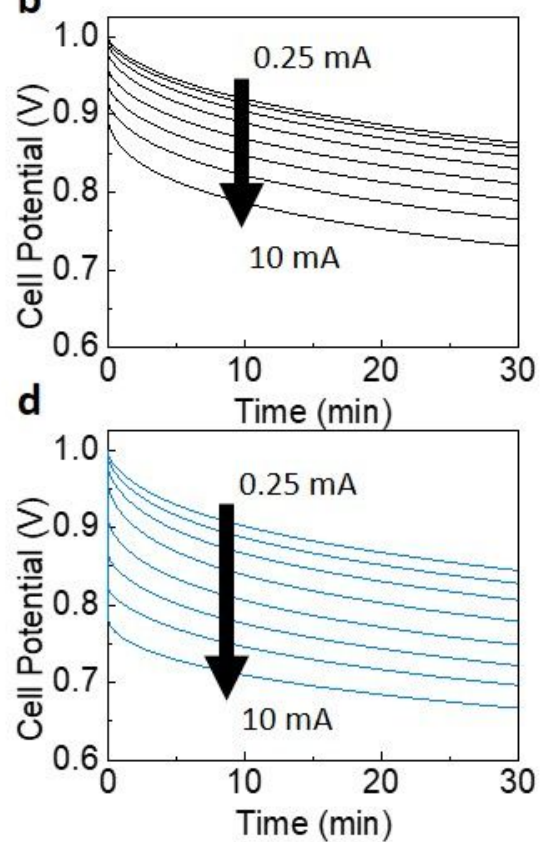

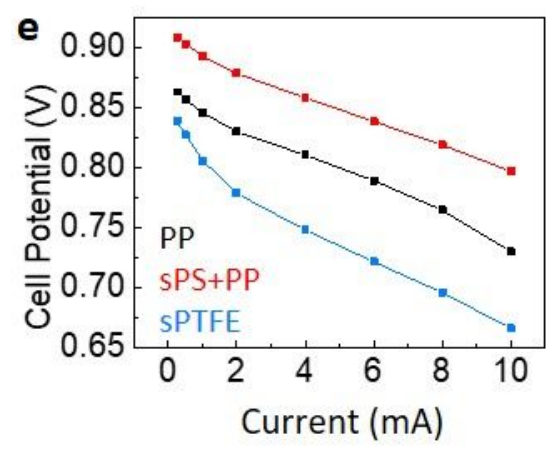

Figure S3. (a) A schematic of the measurement method, in which a constant current (CC) is applied to reach the end potential $\mathrm{V}_{0}$, and subsequently the drop in voltage due to self-discharge is monitored starting at time $t_{\mathrm{oc}}$. Voltage change of a device with a separator of (b) PP (black), (c) sPS+PP (red), (d) sPTFE (blue). The CC varies from 0.25, 0.5, 1, 2, 4, 6, 8, to $10 \mathrm{~mA}$, equivalent to $0.125,0.25,0.5,1,2,3,4$, and $5 \mathrm{~A} / \mathrm{g}$, respectively. (e) Cell potential as a function of input current, taken after 30 minutes of being in open circuit. 


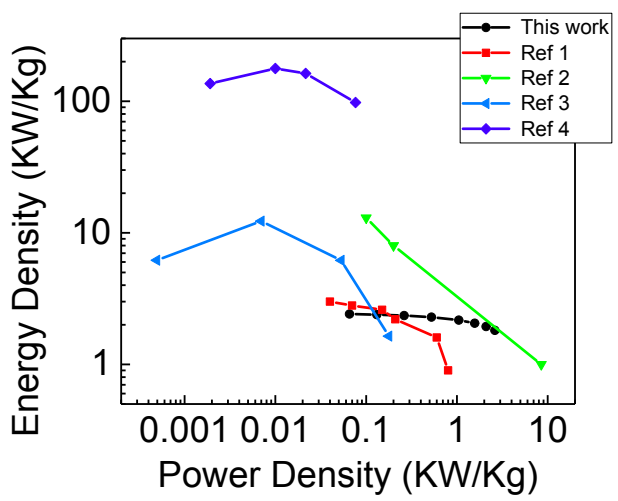

Figure S4. Energy density versus power density in previously reported PEDOT composite supercapacitors and in this work (black markers). Ref 1 (red): PEDOT:PSS/CNT ${ }^{1}$; Ref 2 (green): PEDOT $^{2}$. Ref 3 (light blue): Commercial double-layer supercapacitor. ${ }^{3}$ Ref 4 (dark blue): Li-ion battery. ${ }^{3}$

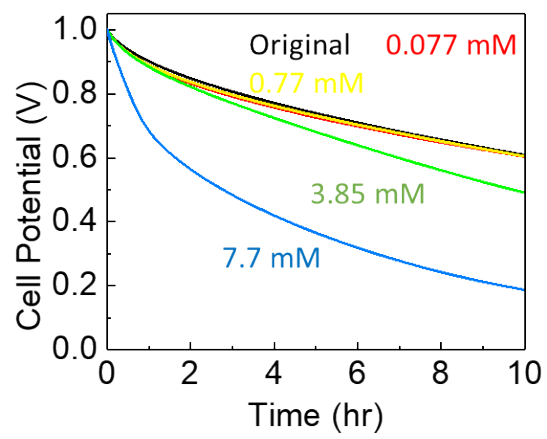

Figure S5. Potential change of supercapacitors with impurities $\left(\mathrm{FeCl}_{3}\right.$ at different $\mathrm{mM}$ concentrations) intentionally added to the electrolyte. The original curve represents the measurement result when no $\mathrm{FeCl}_{3}$ was introduced to device.

Due to the complexity of the electrolyte system, accurate estimation of the adsorption capacity of sPS is difficult. Based on the studies in Refs $28-30$ in the main manuscript, the maximum adsorption capacity of sPS is roughly around $12 \mathrm{mg} / \mathrm{g}(11.55 \mathrm{mg} / \mathrm{g}$ based on Langmuir equation and $12.82 \mathrm{mg} / \mathrm{g}$ based on DKR equation) for $\mathrm{Fe}^{3+}$ ion. In our work, the separator contained $18 \mathrm{mg}$ sPS, theoretically it can absorb $0.216 \mathrm{mg} \mathrm{Fe}^{3+}$ ion ( 7.7 mM for $500 \mathrm{uL}$ electrolyte). As shown above, we found the self-discharge rate was unchanged when the added $\mathrm{Fe}^{3+}$ concentration was lower than $3.85 \mathrm{mM}$, and then the potential dropped significantly when the concentration was higher than $3.85 \mathrm{mM}$. 

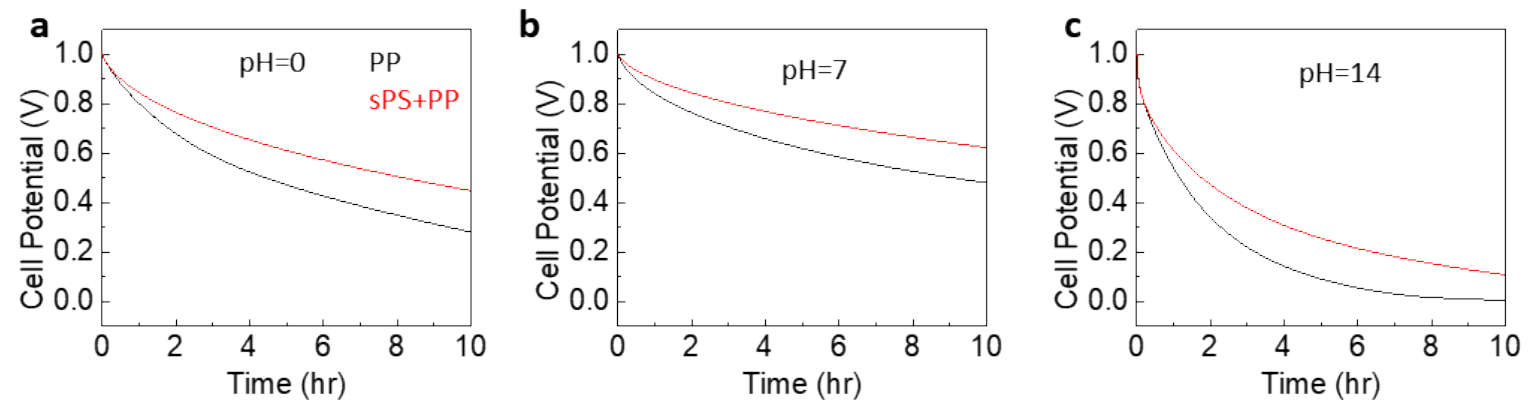

Figure S6. Potential change of supercapacitors with different separators and under different $\mathrm{pH}$, using an electrolyte of (a) $0.5 \mathrm{M} \mathrm{H}_{2} \mathrm{SO}_{4}(\mathrm{pH}=0)$, (b) $1 \mathrm{M} \mathrm{KCl}(\mathrm{pH}=7)$, and (c) $1 \mathrm{M} \mathrm{KOH} \mathrm{(pH=14).}$
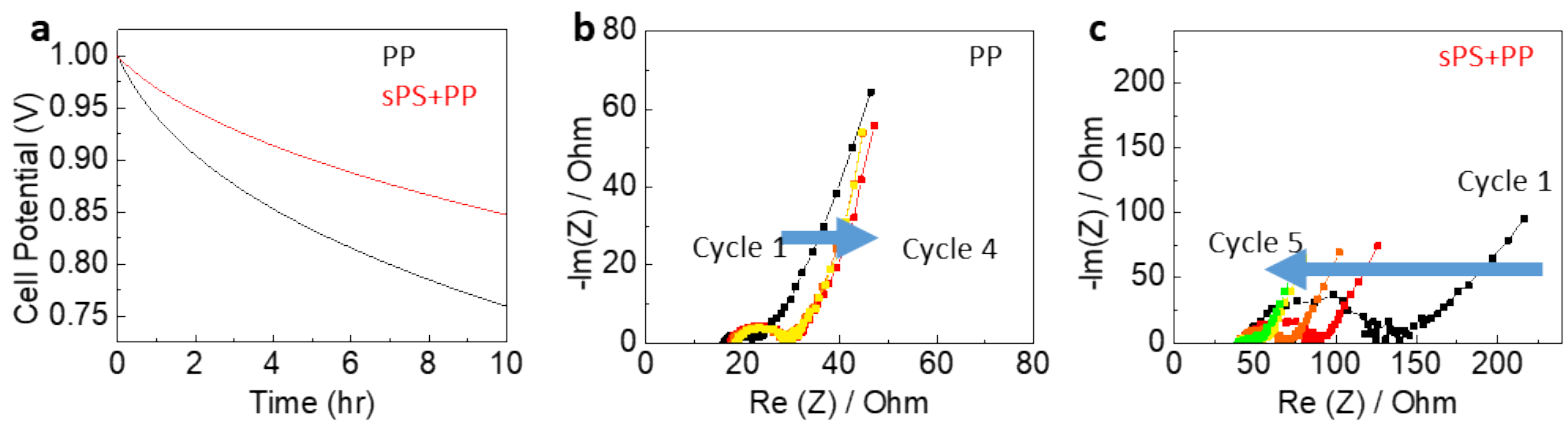

Figure S7. (a) Potential change of supercapacitors with different separators using an organic electrolyte of $0.5 \mathrm{M} \mathrm{TEABF}_{4} / \mathrm{PC}$. Imaginary vs real impedance as a function of charge-discharge cycles, for the device with a separator of (b) PP or (c) sPS+PP. The impedance settled to the same values after cycle 5 . 

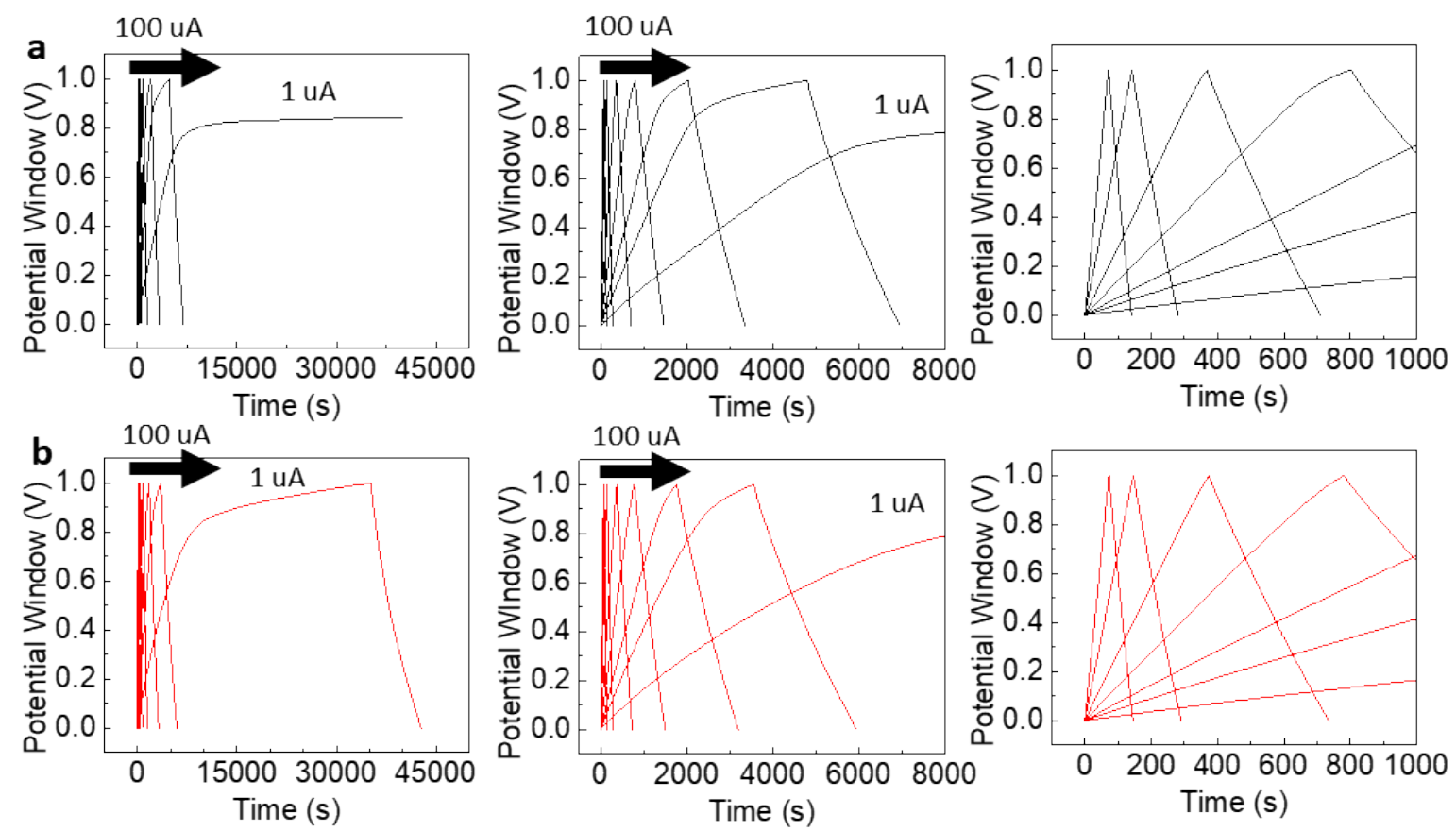

Figure S8. Galvanostatic charging versus time, for the device with (a) a PP or (b) a sPS+PP separator. The charging current is $100 \mathrm{uA}, 50 \mathrm{uA}, 20 \mathrm{uA}, 10 \mathrm{uA}, 5 \mathrm{uA}, 3 \mathrm{uA}$, and $1 \mathrm{uA}$. The right column is the extended figure of $100 \mathrm{uA}$ to $3 \mathrm{uA}$.
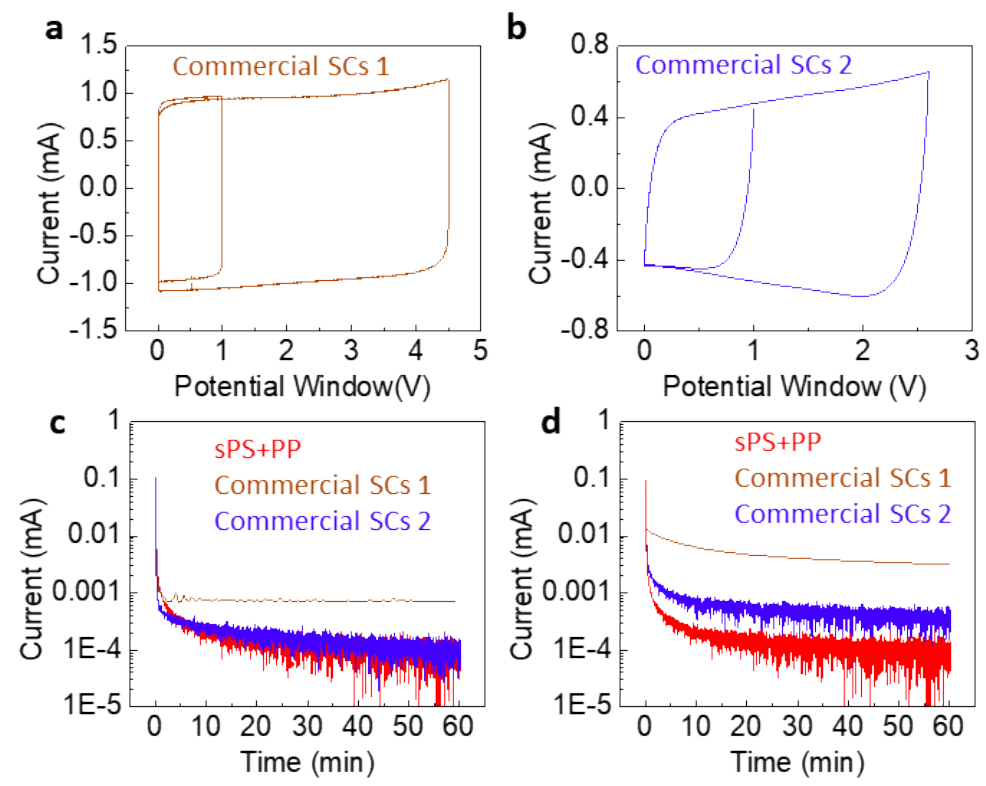

Figure S9. Cyclic voltammetry at $50 \mathrm{mV} / \mathrm{s}$ of (a) commercial supercapacitors SCs 1 (AVX Corporation, BZ054B223ZSB, $22 \mathrm{mF}, 4.5 \mathrm{~V}$ ) and (b) SCs 2 (Seiko Instruments, CPM3225A-2K, $11.5 \mathrm{mF}, 2.6 \mathrm{~V})$. (c) Leakage current comparison of our supercapacitor with sPS-PP separator in organic electrolyte (TEABF 4 in PC), commercial SCs 1 , and commercial SCs 2 at $1 \mathrm{~V}$. (d) Leakage current of sPS-PP based SCs with organic electrolyte at $1 \mathrm{~V}$, commercial SCs 1 at $4.5 \mathrm{~V}$ and commercial SCs at $2.6 \mathrm{~V}$. 

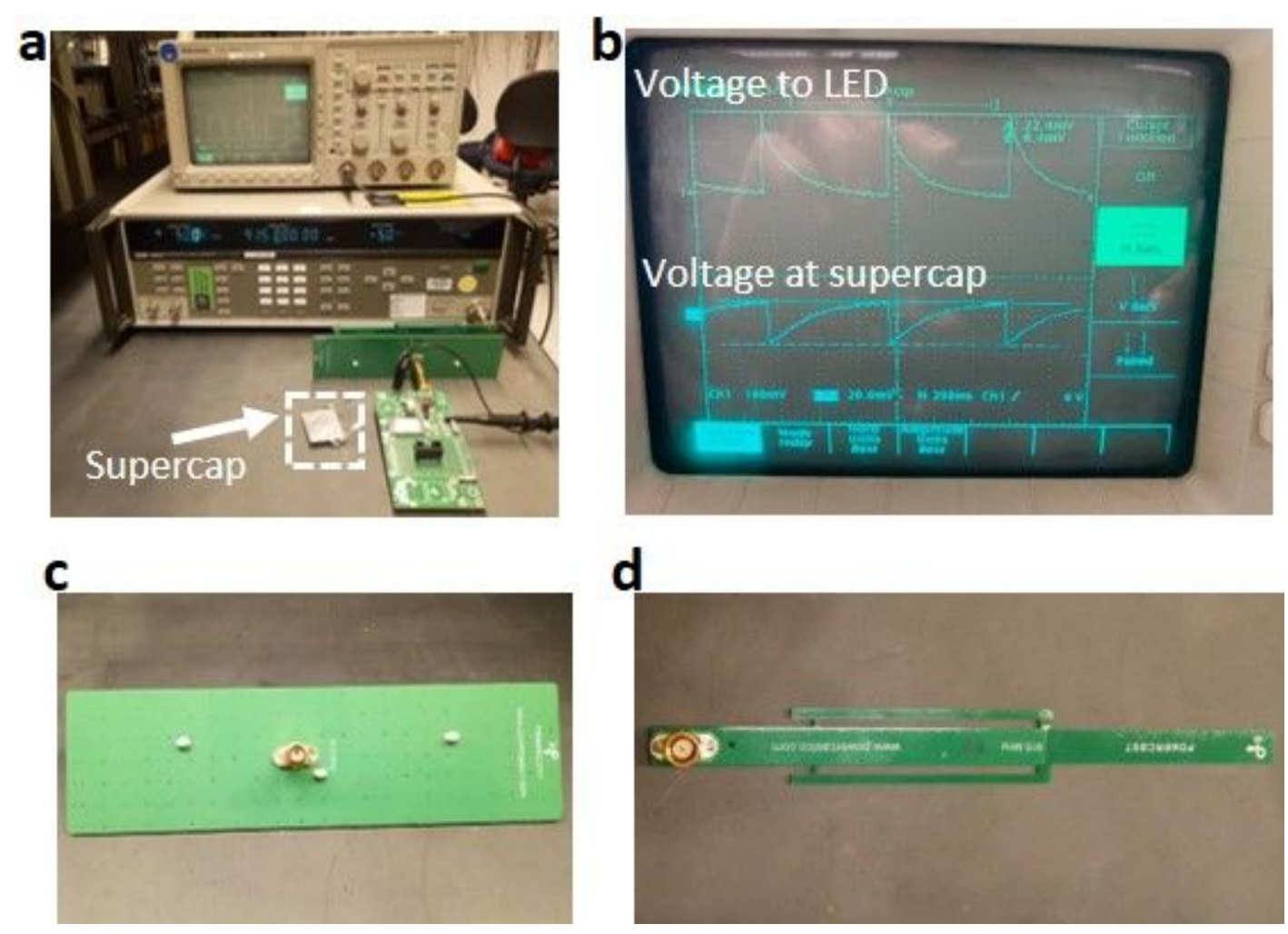

Figure S10. Optical photographs of (a) the RF wireless charging circuit boards, connected to our supercapacitor which in turn is monitored on an oscilloscope. (b) Charging and discharging events measured on the supercapacitor, (c) RF receiver, and (d) RF transmitter. 
Table S1. The fit values for the device with a PP separator under different temperature, taken after cycle 5 . The error in fitting is less than $5 \%$.

\begin{tabular}{lcccl}
\hline $\begin{array}{l}\text { Fitting } \\
\text { equation }\end{array}$ & \multicolumn{2}{c|}{$\mathrm{V}=\mathrm{V}_{0}-\mathrm{a} \ln (\mathrm{t}+\mathrm{b})-\mathrm{m}^{*} \mathrm{t}^{0.5}$} & $\mathrm{~V}=\mathrm{V}_{0}-\mathrm{m}^{*} \mathrm{t}^{0.5}$ \\
\hline $\mathrm{T}\left({ }^{\circ} \mathrm{C}\right)$ & $\mathrm{a}\left(\mathrm{V} \mathrm{s}^{-1}\right)$ & $\mathrm{b}(\mathrm{s})$ & $\mathrm{m}\left(\mathrm{V} \mathrm{s}^{-0.5}\right)$ & $\mathrm{m}\left(\mathrm{V} \mathrm{s}^{-0.5}\right)$ \\
0 & $1.1 \mathrm{E}-4$ & $3.3 \mathrm{E}-8$ & 0.00171 & 0.00172 \\
22 & $1.4 \mathrm{E}-4$ & $3.6 \mathrm{E}-8$ & 0.00251 & 0.00252 \\
30 & $3 \mathrm{E}-14$ & 3.2 & 0.00353 & 0.00354 \\
40 & $9.1 \mathrm{E}-6$ & $3.7 \mathrm{E}-12$ & 0.00403 & 0.00404 \\
50 & $1.11 \mathrm{E}-4$ & $3.2 \mathrm{E}-08$ & 0.00534 & 0.00525 \\
60 & $8.9 \mathrm{E}-12$ & $2.2 \mathrm{E}-14$ & 0.00681 & 0.00681 \\
\hline
\end{tabular}


Table S2. The fit values for the device with a sPS+PP separator under different temperature, taken after cycle 5 . The error in fitting is less than 5\%.

\begin{tabular}{lcccl}
\hline $\begin{array}{l}\text { Fitting } \\
\text { equation }\end{array}$ & \multicolumn{2}{c|}{$\mathrm{V}=\mathrm{V}_{0}-\mathrm{a}^{*} \ln (\mathrm{t}+\mathrm{b})-\mathrm{m}^{*} \mathrm{t}^{0.5}$} & $\mathrm{~V}=\mathrm{V}_{0}-\mathrm{m}^{*} \mathrm{t}^{0.5}$ \\
\hline $\mathrm{T}\left({ }^{\circ} \mathrm{C}\right)$ & $\mathrm{a}\left(\mathrm{V} \mathrm{s}^{-1}\right)$ & $\mathrm{b}(\mathrm{s})$ & $\mathrm{m}\left(\mathrm{V} \mathrm{s}^{-0.5}\right)$ & $\mathrm{m}\left(\mathrm{V} \mathrm{s}^{-0.5}\right)$ \\
0 & $1.9 \mathrm{E}-9$ & $3.6 \mathrm{E}-7$ & 0.00153 & 0.00153 \\
22 & $7.7 \mathrm{E}-9$ & $6 \mathrm{E}-8$ & 0.00197 & 0.00197 \\
30 & 0.00018 & $3.6 \mathrm{E}-8$ & 0.00252 & 0.00253 \\
40 & 0.00024 & $3 \mathrm{E}-8$ & 0.00283 & 0.00283 \\
50 & 0.000178 & $3.5 \mathrm{E}-8$ & 0.00365 & 0.00365 \\
60 & 0.015 & 0.64 & 0.00396 & 0.00440 \\
\hline
\end{tabular}

\section{References}

(1) Antiohos, D.; Folkes, G.; Sherrell, P.; Ashraf, S.; Wallace, G. G.; Aitchison, P.; Harris, A. T.; Chen, J.; Minett, A. I. Compositional Effects of PEDOT-PSS/Single Walled Carbon Nanotube Films on Supercapacitor Device Performance. Journal of Materials Chemistry 2011, 21, 15987-15994.

(2) Duay, J.; Gillette, E.; Liu, R.; Lee, S. B. Highly Flexible Pseudocapacitor Based on Freestanding Heterogeneous MnO2/Conductive Polymer Nanowire Arrays. Physical Chemistry Chemical Physics 2012, 14, 3329-3337.

(3) Dicarmine, P. M.; Schon, T. B.; McCormick, T. M.; Klein, P. P.; Seferos, D. S. DonorAcceptor Polymers for Electrochemical Supercapacitors: Synthesis, Testing, and Theory. Journal of Physical Chemistry C 2014, 118, 8295-8307. 